\title{
Antioxidant and Hypolipidemic Effects of Ipomoea batatas $L$ and Pandanus conoideus Lam Combination on Rats Fed with High Cholesterol Diet
}

\author{
A. A. Ngurah Subawa ${ }^{1 *}$ (D) I. Wayan Putu Sutirta Yasa ${ }^{1}$ D, I. Made Jawi ${ }^{2}$ D, Agung Nova Mahendra $^{2}$ (iD \\ ${ }^{1}$ Department of Clinical Pathology, Faculty of Medicine, Udayana University, Bali, Indonesia; ${ }^{2}$ Department of Pharmacology, \\ Faculty of Medicine, Udayana University, Bali, Indonesia
}

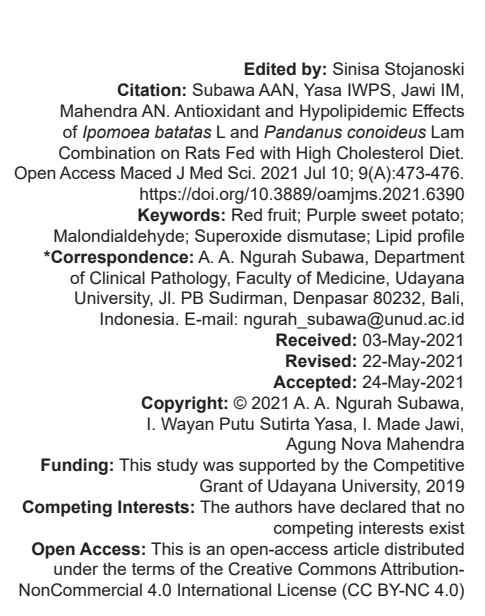

\begin{abstract}
BACKGROUND: Chronic hypercholesterolemia is an important predisposing factor of cardiovascular diseases. The underlying process is commonly associated with oxidative stress.

AIM: This study aimed to evaluate the effects of Ipomoea batatas (IB) L tablet and Pandanus conoideus (PC) Lam extract against oxidative stress and lipid profile in rats.

METHODS: This study used a pre- and post-test control group design. Wistar male rats were randomized into four groups consisting of seven rats each. The groups were control group, PC Lam extract $0.4 \mathrm{cc} / \mathrm{rat} / \mathrm{day}$ (PC group), IB L tablet $200 \mathrm{mg} / \mathrm{rat} /$ day (IB group), and PC $0.2 \mathrm{cc}+\mid \mathrm{B} 200 \mathrm{mg} / \mathrm{rat} / \mathrm{day}$ (PC+|B group). All groups were received high cholesterol diet for 4 weeks. The blood samples at baseline and the end of this study were used for the lipid profile, superoxide dismutase (SOD), and malondialdehyde (MDA) examination. The result was then analyzed with an Analysis of Variance test.

RESULTS: There were significant differences in changes of total cholesterol, Low-density lipoprotein, triglycerides, high-density lipoprotein, MDA, and SOD in the treatment group (PC, IB, PC+IB) compared to the control $(p<0.001)$ The decrease of MDA and increase of SOD were mainly found in the PC+IB group compared to the PC group and IB group $(p<0.05)$. The changes in lipid profiles were mainly found in the PC+IB group and PC group compared to the IB group $(p<0.05)$

CONCLUSION: Administration of PC and IB combination is an effective hypolipidemic agent. This combination has superior antioxidant activity compared to the single-agent (PC or IB) and control.
\end{abstract}

\section{Introduction}

Plant-based medicines are widely used in traditional health care around the world. These medicinal plants may become an alternative treatment for various diseases, including cardiovascular disease [1]. Cardiovascular diseases remain the leading cause of morbidity and mortality worldwide [2]. They have several risk factors including hypercholesterolemia [3] which leads to the accumulation of oxidative stress in the heart and vessel [4], [5], [6]. Antioxidants in diet and nutraceuticals may have beneficial effects to prevent or resolve these processes [6].

Accumulating evidence shows that Ipomoea batatas (IB) L (purple sweet potato) is a promising plant of pharmacological importance. Some studies had proven that IB $L$ extract could reduce blood cholesterol levels and might function as an antioxidant in rats and rabbits that were received high cholesterol diet [7], [8]. A study conducted on hypertensive patients found that $I B L$ extract reduces blood pressure and oxidative stress [9]. Metalloenzyme plays a major role in antioxidant defense against oxidative stress in the body is Superoxide Dismutase (SOD) [10]. Its expression in blood vessel endothelium was increasing after administration of IB L [11]. Anthocyanin is the main component of various flavonoids in IB $L$ extract that had been proved to have strong antioxidant properties [7], [8], [9], [11]. A previous study developed tablet preparation since the tablet was relatively more stable, low price for packaging, easily swallowed and can be packed properly. However, the study showed that the potency of IB $L$ tablet was weaker than liquid preparations [12]. Therefore, it is necessary to find an alternative strategy to improve the antioxidant efficacy by combining IB $L$ tablet with another potential tropical plant.

Pandanus conoideus (PC) Lam (Red Fruit) is another abundant source of antioxidants, since it contains flavonoids, beta carotene, and Vitamin $E$ [13]. Research on the effects of PC Lam extract in rats given a maximum load of physical activity showed that PC Lam extract was able to prevent oxidative stress by increasing SOD levels and reducing malondialdehyde (MDA) in the blood. MDA 
is an indicator of lipid peroxidation due to oxidative stress [14]. This fruit was also found to reduce Lowdensity lipoprotein (LDL) levels in rats [15]. Based on these issues, this study evaluates the combined effect of IB $L$ tablet and PC Lam extract against oxidative stress and lipid profile in rats that received a high cholesterol diet.

\section{Materials and Methods}

\section{Animal models}

This experimental study was a randomized pre-and post-test control group design. The Ethics Committee of Faculty of Medicine, Udayana University, Bali, Indonesia had been approved this study (No: 3070/UN14.2.2.VII.14/LP/2019). The method for preparation IB $L$ tablet was the same as the previous study by Yasa et al. [12] and PC Lam oil was extracted according to the previous study by Sugiritama et al. [16].

Twenty-eight male Wistar rats (4 months, 200-250 g) were randomly selected. They were divided into four groups; each group consists of seven animals. The control group only received a high cholesterol diet per oral for 4 weeks. Whereas the PC group received $\mathrm{PC}$ extract per oral in a dose of $0.4 \mathrm{cc} / \mathrm{rat} / \mathrm{day}$ and a high cholesterol diet for 4 weeks. IB group received IB tablet per oral in a dose of $200 \mathrm{mg} / \mathrm{rat} / \mathrm{day}$ and a high cholesterol diet for 4 weeks. $\mathrm{PC}+\mathrm{IB}$ group received $\mathrm{PC}$ extract per oral $0.2 \mathrm{cc} / \mathrm{rat} /$ day, IB tablet per oral in a dose of $100 \mathrm{mg} / \mathrm{rat} /$ day, and a high cholesterol diet for 4 weeks. Before the treatment of all groups, blood samples were taken for quantification of MDA level, SOD level, and lipid profile, as pre-test data. After 4 weeks of treatment, the blood samples were taken as post-test data. Data were analyzed using the oneway Analysis of Variance test followed by the Post Hoc (Duncan) test to measure specific differences between groups.

\section{Lipid profile, SOD, and MDA examinations}

Blood samples for the lipid profile, SOD, and MDA examination were collected from retroorbital plexus. They were centrifuged for $10 \mathrm{~min}$ at $1500 \mathrm{rpm}$. For further analysis, the supernatants were collected and stored at $20^{\circ} \mathrm{C}$. The serum lipid profile (total cholesterol, LDL, triglycerides, and Highdensity lipoprotein [HDL]) in $\mathrm{mg} / \mathrm{dL}$ were measured using Colorimetric kits from Azmun (Tehran, Iran). The MDA examination in $\mathrm{nmol} / \mathrm{mL}$ used thiobarbituric acid reactive substances assay kit, meanwhile the SOD level quantification in $\mathrm{nmol} / \mathrm{mL}$ used total antioxidant status (Randox) kit.

\section{Results}

\section{Antioxidant activity}

Measurement of MDA and SOD levels in rats showed a significant increase of MDA and a decrease of SOD in the control group. There were significant differences in the changes of MDA and SOD in the treatment group $(\mathrm{PC}, \mathrm{IB}$, and $\mathrm{PC}+\mathrm{IB})$ compared to the control $(p<0.001)$. The decrease in MDA and the increase in SOD were mainly found in the $\mathrm{PC}+\mathrm{IB}$ group compared to the PC group and the IB group $(p<0.05)$ (Table 1).

Table 1: The changes of MDA and SOD level before and after the treatment in rats

\begin{tabular}{lll}
\hline Groups & \multicolumn{2}{l}{ Means \pm Standard deviation $(\mathrm{nmol} / \mathrm{mL})$} \\
\cline { 2 - 3 } & MDA & SOD \\
\hline Control & $8.17 \pm 0.49^{\dagger}$ & $-59.06 \pm 3.45^{\dagger}$ \\
PC & $2.09 \pm 0.46^{* \dagger}$ & $-27.78 \pm 5.59^{* \dagger}$ \\
IB & $4.53 \pm 0.38^{* \dagger}$ & $-42.69 \pm 7.41^{* \dagger}$ \\
PC+IB & $1.11 \pm 0.31^{*}$ & $-16.26 \pm 6.12^{*}$ \\
\hline PC: Pandanus conoideus Lam; IB: Ipomoea batatas L; ${ }^{*}$ Significant different with control $(p<0.001) ;$ \\
'Significant different with PC+IB $(p<0.05)$. SOD: Superoxide dismutase, MDA: Malondialdehyde.
\end{tabular}

\section{Hypolipidemic effect}

The changes of lipid profile (total cholesterol, LDL, triglyceride, and HDL) before and after the treatment (pre-test and post-test) in the control group and treatment groups (PC, IB, and $\mathrm{PC}+\mathrm{IB})$ are presented in Table 2. A significant increased (post-test and pre-test) in total cholesterol, LDL, and triglyceride levels were observed in the control group, whereas HDL level decreased. There were significant differences in the changes in lipid profile in the treatment group (PC, $I B, P C+I B)$ compared to the control $(p<0.001)$. The decrease in total cholesterol and LDL and the increase in HDL were especially found in the $\mathrm{PC}+\mathrm{IB}$ group and $\mathrm{PC}$ group compared to the IB group $(p<0.05)$. However, the PC group had the best effect in decreasing triglyceride levels compared to other groups $(p<0.001)$.

Table 2: The changes of total cholesterol, LDL, triglyceride, and HDL levels before and after the treatment in rats

\begin{tabular}{|c|c|c|c|c|}
\hline \multirow[t]{2}{*}{ Groups } & \multicolumn{4}{|c|}{ Means \pm Standard deviation $(\mathrm{mg} / \mathrm{dL})$} \\
\hline & Total cholesterol & LDL & Triglyceride & $\mathrm{HDL}$ \\
\hline Control & $134.09 \pm 2.26^{\dagger}$ & $73.19 \pm 2.38^{\dagger}$ & $70.30 \pm 4.32^{\dagger}$ & $-61.74 \pm 3.35^{\dagger}$ \\
\hline PC & $15.42 \pm 2.62^{*}$ & $13.52 \pm 2.20^{*}$ & $8.85 \pm 6.14^{\star \dagger}$ & $-11.55 \pm 2.17^{*}$ \\
\hline IB & $45.63 \pm 4.78^{*^{\dagger}}$ & $28.49 \pm 3.71^{\star \dagger}$ & $33.46 \pm 5.69^{* \dagger}$ & $-31.67 \pm 2.52^{* \dagger}$ \\
\hline$P C+I B$ & $18.09 \pm 3.42^{*}$ & $12.13 \pm 5.82^{\star}$ & $25.58 \pm 4.74^{*}$ & $-9.46 \pm 7.29^{\star}$ \\
\hline
\end{tabular}

\section{Discussion}

In this study, Wistar rat that received high cholesterol diet for 4 weeks (control group) causes a significant increase in cholesterol, LDL, and triglycerides levels, and a significant decrease in HDL level. A high cholesterol diet also causes a decrease in SOD and an 
increase in MDA as evidence of oxidative stress due to hypercholesterolemia. The increase of oxidative stress in hypercholesterolemia is caused by an increase in the activity of NADPH enzyme, resulting in the increase of superoxide ions production and the decrease of endogenous antioxidant enzyme synthesis [5]. Oxidative stress on hypercholesterolemia is also caused by an increase in the accumulation of total cholesterol in cells, thereby increasing MDA biogenesis as a marker of oxidative stress, and a decrease in SOD reserves because it is used to neutralize free radicals enhancement due to hypercholesterolemia [17].

In this study, there were significant differences in lipid profile changes in the treatment groups (PC, IB, $\mathrm{PC}+\mathrm{IB}$ ) compared to the control group. The $\mathrm{PC}+\mathrm{IB}$ group showed similar benefits to the PC group in increasing HDL and decreasing total cholesterol and LDL. Therefore, these groups had a better hypolipidemic effect than the IB group. Whereas treatment with the combination $\mathrm{PC}+\mathrm{IB}$ provided a superior antioxidant effect compared to single compound treatment $(p<0.05)$. PC Lam is a natural source of high antioxidants, including carotenoids, betacarotene, tocopherols, and unsaturated fatty acids which include decanoic acid, linolenic acid, linoleic acid, and oleic acid. PC Lam had been proven as a non-toxic drug [18], thus it is relatively safe to consume for a long time. In this study, the rats have received a dose of $0.2-0.4 \mathrm{cc}$ which had been proven to resolve oxidative stress in the preeclampsia animal model according to Sugiritama et al. (2016) [16]. In addition, many animal studies had confirmed the antioxidant activity of IB due to its secondary metabolite anthocyanin, as well as its safety at appropriate doses [7], [8], [9], [19].

The hypolipidemic effect of IB may due to several mechanisms, namely regulation of cholesterol synthesis through inhibition of adipogenic enzyme expression by a decrease in transcription factors. Extracts with high anthocyanin content might also reduce the expression of acetyl-coenzyme A synthetase [20]. The decrease in LDL and cholesterol levels in the PC group could be presumably associated with the antioxidant mechanism and the inhibition of enzymes for cholesterol synthesis in the liver. The results of this study were consistent with other studies conducted on diabetic rats in which the administration of PC extract caused a significant decrease in LDL [15].

This study showed the combined administration had better antioxidant potency than single administration and required lower drug concentrations to produce the same and even better antioxidant effects. This is because each extract contains different active metabolites which may act in different targets/mechanisms. PC Lam contains $\alpha$-tocopherol and $\beta$-carotene which function as antioxidants [21], while IB L contains anthocyanins, flavonoids that act at various stages of oxidative stress, hence they may have synergistic antioxidant effects [22], [23]. One of the indicators for $\mathrm{PC}$ and IB antioxidant activity was a decrease of MDA levels in all treatment groups. The results of this study were consistent with studies conducted on rats testes protected by PC [24] and studies conducted in hypertensive patients protected by IB [9].

The types of anthocyanins in IB that have been studied are mainly cyanidin and peonidin which are quite strong antioxidants [25], [26]. Anthocyanins can donate electrons stronger than, L-Ascorbic acid and butylated hydroxytoluene which are standard antioxidants commonly used in laboratory experiments so that anthocyanins are strong antioxidants. Thus, the IB extract in tablet form decreases MDA and increases SOD through its electron donation activity. Anthocyanins in IB are also known to reduce oxidative stress by eliminating mitochondrial lipid peroxidation and mitochondrial transmembrane electrical potential due to oxidative stress [27]. In addition, the decrease of oxidative stress might be also resulted from the scavenging of reactive oxygen species by carotenoid [28] and $\alpha$-tocopherol [29] from PC.

The limitation of this study was the dosage form for combining $\mathrm{PC}$ and $\mathrm{IB}$, since this study did not utilize the combination tablet containing both $\mathrm{PC}$ and $\mathrm{IB}$, however, it is necessary to prove the superiority of these compound combinations before proceeding to the next phase. The development of tablet from plant extract needs several steps to achieve the right dosing and composition. Considering the superior effect of the combination in this study, further research in tablet preparation optimization is needed.

\section{Conclusion}

The combination of PC Lam and IB L improved lipid profile, increased SOD level, and decreased MDA level. Therefore, this combination is effective as a hypolipidemic agent and exerts superior antioxidant effects compared to the single-agent ( $\mathrm{PC}$ or $\mathrm{IB}$ ), and the control group.

\section{References}

1. Al-Snafi AE. Medicinal plants for prevention and treatment of cardiovascular diseases-a review. IOSR J Pharm. 2017;7(4):103-63. https://doi.org/10.9790/3013-070401103163

2. Mohamed NA. Prevalence of risk factors for diabetes mellitus and hypertension among adult in Tabuk-Kingdom of Saudi Arabia. Open Access Maced J Med Sci. 2019;7(5):831-7. https://doi.org/10.3889/oamjms.2019.046 PMid:30962848

3. Zarate A, Manuel-Apolinar L, Saucedo R, HernandezValencia M, Basurto L. Hypercholesterolemia as a risk factor for cardiovascular disease: Current controversial therapeutic management. Arch Med Res. 2016;47(7):491-5. https://doi. 
org/10.1016/j.arcmed.2016.11.009

\section{PMid:28262189}

4. Jarukamjorn K, Sinthorn W, Pimson C. The relation of oxidative stress and hypercholesterolemia. Thai $\mathrm{J}$ Toxicol. 2014;29(1-2):57-69.

5. Csonka C, Sarkozy M, Pipicz M, Dux L, Csont T. Modulation of hypercholesterolemia-induced oxidative/nitrative stress in the heart. Oxid Med Cell Longev. 2016;2016:3863726. https://doi. org/10.1155/2016/3863726

PMid:26788247

6. Senoner T, Dichtl W. Oxidative stress in cardiovascular diseases: Still a therapeutic target? Nutrients. 2019;11(9):1-25. https://doi.org/10.3390/nu11092090

PMid:31487802

7. Jawi IM, Yasa IW, Mahendra AN, Sumardika IW. Effective dose and safety profile of purple sweet potato tablet preparation in rats with high cholesterol diet. Biomed Pharmacol J. 2020;13(2):66571. https://doi.org/10.13005/bpj/1930

8. Yasa IW, Jawi IM. Antioxidant potential and hypolipidemic effects of combined purple sweet potato (Ipomoea batatas L.) tuber extract with honey in rats given high cholesterol feed. Bali Med J. 2017;3(3):565-9. https://doi.org/10.15562/bmj.v6i3.716

9. Jawi IM, Yasa IW, Subawa AA, Suprapta DN. Comparison of potential antihypertensive and antioxidant between aqueous extract of purple sweet potato tuber and captopril in hypertensive patients. J Biol Agric Healthc. 2015;5(14):128-33. https://doi. org/10.15562/bmj.v5i2.217

10. Younus $H$. Therapeutic potentials of superoxide dismutase. Int $J$ Health Sci. 2018;12(3):88-93

PMid:29896077

11. Jawi IM, Indrayani W, Arijana IG, Subawa AA, Suprapta DN Aqueous extract of purple sweet potato increased SOD-2 and SOD-3 expression on human umbilical vein endothelial cells in vitro. J Biol Agric Healthc. 2016;6(2):103-10.

12. Yasa IW, Jawi IM, Astawa P. The comparative effect of liquid and tablet preparation of purple sweet potato (Ipomoea batatas L) extract to lipid profile, MDA, and SOD level in male wistar rats after given high cholesterol diet. J Glob Pharma Technol. 2018;10(7):356-61.

13. Sinaga FA, Purba PH, Sinaga RN, Silaban R. Effects of red fruit (Pandanus conoideus Lam) oil on exercise endurance and oxidative stress in rats at maximal physical activity. Open Access Maced J Med Sci. 2020;8:164-9. https://doi.org/10.3889/ oamjms.2020.3428

14. Tsikas D. Assessment of lipid peroxidation by measuring malondialdehyde (MDA) and relatives in biological samples: Analytical and biological challenges. Anal Biochem. 2017;524:13-30. https://doi.org/10.1016/j.ab.2016.10.021 PMid:27789233

15. Agnesa OS, Waluyo J, Prihatin J, Lestari SR. Potensi buah merah (Pandanus conoideus Lam.) dalam menurunkan kadar LDL darah tikus putih. Bioeksperimen. 2017;3(1):48-57. https:// doi.org/10.23917/bioeksperimen.v3i1.3670

16. Sugiritama IW, Ratnayanti IG, Wiryawan IG, Wahyuniari IA, Linawati NM, Arijana IG. Effect of red fruit oil (Pandanus conoideus Lam) on animal model of preeclampsia. Int $J$ Sci Res. 2016;5(7):1770-3. https://doi.org/10.21275/v5i7. art2016604
17. Singh UN, Kumar S, Dhakal S. Study of oxidative stress in hypercholesterolemia. Int J Contemp Med Res. 2017;4(5):1204-7.

18. Wismandanu O, Maulidya I, Indariani S, Batubara I. Acute toxicity of red fruits (Pandanus conoideus Lamk) oil and the hepatic enzyme level in rat. J Phytopharmacol. 2016;5(5):176-8.

19. Sugiritama IW, Wahyuniari IA, Ratnayanti IG, Linawati NM, Wiryawan IG, Komalasari NL, et al. The effect of purple sweet potato (Ipomea batatas $\mathrm{L}$ ) ethanol extract on estrogen receptor alpha $(\mathrm{ER} \alpha)$ and SOD mRNA expression in the menopauseliver animal model. Bali Med J. 2020;9(3):645-8. https://doi. org/10.15562/bmj.v9i3.1784

20. Lee B, Lee M, Lefevre M, Kim HR. Anthocyanins inhibit lipogenesis during adipocyte differentiation of 3T3-L1 preadipocytes. Plant Foods Hum Nutr. 2014;69(2):137-41. https://doi.org/10.1007/s11130-014-0407-z

PMid:24682657

21. Rohman A, Sugeng $R$, Che Man YB. Characterizaton of red fruit (Pandanus conoideus Lam) oil. Int Food Res J. 2012;19(2):563-7.

22. Di Gioia F, Tzortzakis N, Rouphael Y, Kyriacou MC, Sampaio SL, Ferreira IC, et al. Grown to be blue-antioxidant properties and health effects of colored vegetables. Part II: Leafy, fruit, and other vegetables. Antioxidants (Basel). 2020;9(2):97-138. https://doi.org/10.3390/antiox9020097 PMid:31979214

23. Khoo HE, Ng HS, Yap WS, Goh HJ, Yim HS. Nutrients for prevention of macular degeneration and eye-related diseases. Antioxidants (Basel). 2019;8(4):85-100. https://doi.org/10.3390/ antiox8040085 PMid:30986936

24. Widayati A, Widjiati, Hayati A. Effects of red fruit (Pandanus conoideus Lam) oil on malondialdehyde level and spermatozoa quality in Mice (Mus musculus) exposed to monosodium glutamate. Folia Med Indones. 2018;54(2):84-8. https://doi. org/10.20473/fmi.v54i2.8855

25. Laksmiani NP, Paramita NL, Wirasuta IM. In vitro and in silico antioxidant activity of purified fractions from purple sweet potato ethanolic extract. Int J Pharm Pharm Sci. 2016;8(8):177-81.

26. Ayeleso TB, Ramachela K, Mukwevho E. A review of therapeutic potentials of sweet potato: Pharmacological activities and influence of the cultivar. Trop J Pharm Res. 2016;15(12):275161. https://doi.org/10.4314/tjpr.v15i12.31

27. Tang Z, Li M, Zhang X, Hou W. Dietary flavonoid intake and the risk of stroke: A dose-response meta-analysis of prospective cohort studies. BMJ Open. 2016;6(6):e008680. https://doi. org/10.1136/bmjopen-2015-008680 PMid:27279473

28. Fiedor J, Burda K. Potential role of carotenoids as antioxidants in human health and disease. Nutrients. 2014;6(2):466-88. https://doi.org/10.3390/nu6020466 PMid:24473231

29. Wu CM, Cheng YL, Dai YH, Chen MF, Wang CC. $\alpha$-tocopherol protects keratinocytes against ultraviolet $A$ irradiation by suppressing glutathione depletion, lipid peroxidation and reactive oxygen species generation. Biomed Rep. 2014;2(3):419-23. https://doi.org/10.3892/br.2014.236

PMid:24748986 